\title{
The Attitudes of the Academic School Community towards Applying Distance Learning in the High School Stage
}

\author{
Samirah Ahmed Al-Jifri \\ Educational Technologist and Physics Science Supervisor in Ministry of Education \\ KSA/ Jeddah
}

\begin{abstract}
This paper focuses on distance learning in the public education. This is to know how far the academic community in the high school stage will accept it and what benefits they would get of this. It aims at knowing the attitudes of the academic categories towards the appropriateness of distance learning for the high school stage by using the survey. The study had been done on a haphazardly harmonious category sample (320). It is divided into categories; teachers, principals, parents and students.

The most members of the sample agree on the possibility of applying distance learning in the high school for several reasons focusing on the flexibility of this type of education and its capability to adapt to the learner's circumstances. While some of the members of sample stress on necessity of the harmony of education with technology and developments of the age. Also, it should exploit Mania of students with Internet and directing it properly through education portal.

The researcher has concluded to some specifications and conditions to make distance learning proper for the high school. Finally, she recommends making studies and researches about the effects of that on the students of the high school from all sides.
\end{abstract}

Keywords: Distance Learning, High School Stage, the Academic Community.

\section{Introduction}

In light of the growing and fast development in the technologies of information and telecommunications, a lot of public and private educational institutions, in both of advanced or developing countries show a great interest in using the potentials of those modern means of multimedia. There is also a severe competition and a race to benefit from and make use of them in the field of introducing and spreading academic curriculum as well as training programs through what is known as distance learning or the virtual education. That is an alternative for the traditional education that requires the existence of the learner and the teacher at a certain place and at a certain time, or as a supporting means to the traditional education.

Attention of specialists to enter this technology has come from their experiments and researches that emphasized the positive side of distance learning on the undergraduate students as well as their attitudes, according to Al-Mubarak [1], Hussain [2].

Shawashreh [3] concluded the importance of adults' education that provides learning opportunities for whoever desires and is capable. The research study concluded that distance learning must be greatly cared about by the Arabian governments. That should be done so that it can expand to include all different academic majors.

Grunewald and others [4] concluded with success of distance learning. Enthusiasm, satisfaction and excellence also appeared in the sample of the faculty of medicine students at the virtual University of Bavaria.

Nashwan [5] showed that distance learning makes it easy for the woman and the mother to complete their higher education via the educational technologies and the appropriate time for them.

Samirah [6] emphasized the appropriateness of distance learning in developing the skills of educational supervision as well as the suitability of virtual education for the stages in the public education.

The importance of this kind of education is that it aims at conveying the educational or the training program to a very large number of learners at their locations wherever the suitable technology is available needless of their attendance to the classes. In addition, it achieves the principle of equality in giving equal educational chances to the learners besides the quality of its programs as well as its low costs if compared with the traditional education. The main advantages of distance learning can be summarized in the following:

i. Providing learning opportunities to the individuals who are unable to continue their education in a method other than this one because of their social, work or health circumstances or for the geographical distances and difficulties in transportation.

ii. Providing learning chances for those individuals for whom the traditional methods of learning have become unsuccessful or unfavorable.

iii. Strengthening the learners as they have no longer become limited to previously selected curricula 
or the location where the academic institution exists. Also, they can learn at any time that is suitable for them and in the speed that is appropriate for their capabilities.

iv. The modern technologies provided the possibility of displaying the academic subjects in innovative and encouraging methods. It is provided in the method of the guiding explorer through use of interactive methods to engage the learner in the educational process. This enhances the probability of deep comprehension for them.

v. The modern technologies with their various potentials have assisted to provide the possibility of co-operation and participation. For instance, the Internet allows synchronized and unsynchronized communication among the students themselves and between them and other colleagues and educators regardless of their locations, according to Visser [7].

Increased attention to use distance learning has grown at the academic institutions as a result of the challenges facing those institutions in the information age. The most prominent challenges are the following:

i. The critical economic circumstances in many countries which led to the shrink of governmental financial support that is usually granted to the academic institutions.

ii. The huge stresses on the academic institutes to reduce the expenses on one hand and to enhance the quality level of education on the other hand.

iii. Increasing the opportunities for joining the educational institutions to include accepting the applications of all people desiring to continue the university education without any distinctions.

iv. The sharp competition between the public and the private educational institutes to attract the largest possible number of individuals wanting to continue the university studies.

According to Virkus [8], Morino [9], the academic institutions being affected by the modern technologies of information and telecommunications,

As the education in the high schools is an integral part of the public education, public and private, they have also been affected by those modern attitudes and methods in education.

Samirah [6] also indicates that distance learning stresses liberty from the restrictions of the classroom that is limited to the time and location. Thus, distance learning is distinguished with flexibility to suit the learners' needs.

This worksheet has cared about distance learning in the high school stage because of the scarcity of studies in this field and in the Arab countries, in particular. That is to know the acceptance of related individuals in entering this system in the high school stage and what the benefit of that.

Does the academic community support the system of distance learning in the stage of high school in the Kingdom of Saudi Arabia?

\section{Objectives of the Study}

In general, this study aims at knowing the attitudes of the categories of the academic community towards distance learning in the stage of high school in the Kingdom of Saudi Arabia in Jeddah country. This is by way of using a survey.

The study had been done by selecting a haphazard harmonious sample (320) people. The sample is divided into categories as follows:

i. Teachers in the high school stage (69

Teachers).

ii. Principals at high schools (37 Principals).

iii. Parents; fathers and mothers and guardians (124 Parents).

iv. Students at high schools (90 Students).

\section{The Results}

To know the attitudes of the categories of the academic community towards applying distance learning in the high school stage, the percentages of the numbers of supporters \& anti-supporters have been worked out from each category of the sample of study as shown in Figure 1:

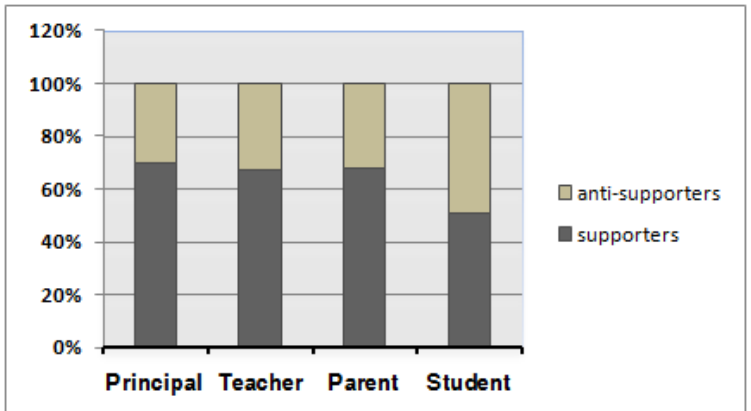

Figure 1. Diagram of percentage of supporters \& antisupporters of distance learning

\subsection{The number and percentage of supporters from each category as well as the causes according to them as follows:}

There is a positive agreement on the possibility of applying distance learning in the high school stage (63\%) of the total number of the sample of study. It is displayed in the following table: 
Table1. Percentage of supporters of distance learning

\begin{tabular}{|c|c|c|c|}
\hline 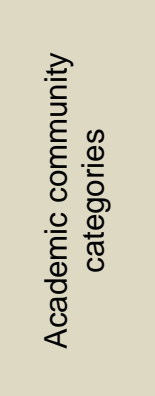 & 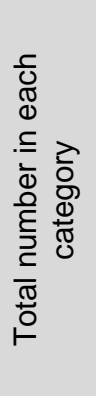 & 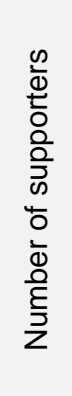 & 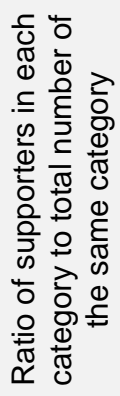 \\
\hline Principal & 37 & 26 & $70 \%$ \\
\hline Teacher & 69 & 46 & $67 \%$ \\
\hline Parent & 124 & 84 & $68 \%$ \\
\hline Student & 90 & 46 & $51 \%$ \\
\hline Total & 320 & 202 & $63 \%$ \\
\hline
\end{tabular}

Whereas all individuals of the sample of study support the possibility of applying distance learning for the high school stage, according to them for the following reasons:

i. It is suitable for the students having special circumstances, concerning health or social circumstances.

ii. It is suitable for the students who are geographically far away from traditional academic study.

iii. Making use of the technology hallucination of the students so that it can benefit them and direct them soundly.

iv. Harmony with new trends of this age because developing is an important requirement. It cannot be achieved unless entered from the gates of education.

v. It saves money, time and effort.

vi. It solves the problem of the lack of efficient teachers.

vii. It grants employment opportunities and reduces the unemployment of those having the bachelor degrees.

\subsubsection{Responses of the sample of the study for the previous reasons are as follows:}

The principals of high schools, with a ratio of (70\%) from the total number of this category agreed on the appropriateness of distance learning for the high school stage, according to them for the following reasons:

i. It reduces the crowdedness of students in the traditional classrooms.

ii. It achieves the flexibility required in education.

iii. It raises the level of performance of the teachers and enhances competition among them.

iv. It makes the students get accustomed to communication with the outside world under an educational supervision. v. It is suitable for the education of adults.

vi. It prepares the student to join the university.

vii. It solves the problem of external academic studying.

The teachers at the high schools, with a ratio of (67\%) from the total number of this category agreed on the appropriateness of distance learning for the high school stage, according to them for the following reasons:

i. It helps in self-learning and the students feel responsible for their education.

ii. It assists in developing the skills of reading and scientific research for the students.

iii. It develops the high thinking skills of the students, if applied correctly.

iv. It creates a big challenge for the teachers to prove their skills at a distance.

v. It gives the teachers enough time to develop themselves instead of being devoted to traditional works.

vi. It qualifies the student gradually to study abroad in advanced countries.

vii. The teachers do not need to stand up during the academic day.

Parents and guardians, with a ratio of (68\%) from the total number of this category agreed on the appropriateness of distance learning for the high school stage, according to them for the following reasons:

i. Using the leisure time of the students fruitfully.

ii. Learning is a necessity for life and the student must study in all possible circumstances.

iii. It creates employment opportunities for the ladies whose family circumstances prevent them from working outside the house.

iv. It is suitable to whoever desires to study and work at the same time.

v. It is suitable for the relatives of the students who travel a lot and whose jobs require continuous travelling.

vi. It solves the problem of private tutoring.

vii. It reduces pollution of the environment, particularly in the crowded cities.

viii. It decreases the possibility of mixing with bad companions within the fences of the school.

ix. It is suitable for conservative families who desire studying at home for their kids.

Students of the high school stage, with a ratio of $(51 \%)$ from the total number of this category agreed on the appropriateness of distance learning for the high school stage, according to them for the following reasons:

i. It is an appropriate means for communication with the teacher outside the fences of the school. 
ii. It helps the shy students to be courageous in dialogues or discussions.

iii. It gives the student more time for studying.

iv. It gives the students an opportunity to select the teachers whom they like.

v. It is a means to exchange cultures and learn languages.

vi. It makes learning enjoyable and exciting.

vii. It makes learning reachable.

viii. It enables the students to travel during the academic study.

ix. It relieves the students from carrying school bags.

x. It makes the homework clear and readable to those who do not have the skill of beautiful handwriting.

xi. It relieves the students from daily attendance and getting up early.

3.2. The number and percentage of antisupporters from each category as well as the causes according to them as follows:

Some of the samples of study, with a ratio of (37\%) look negatively at the possibility of application of distance learning in the high school stage from all categories of the study as shown in the following table:

Table2. Percentage of anti-supporters of distance

\begin{tabular}{|c|c|c|c|}
\hline 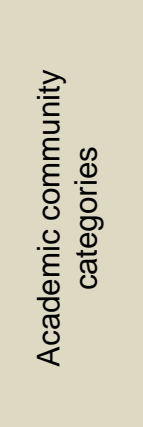 & 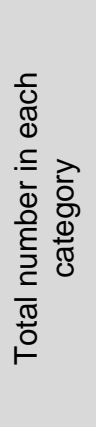 & 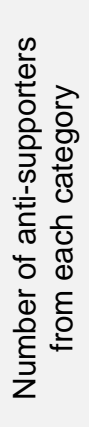 & 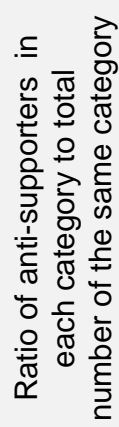 \\
\hline Principal & 37 & 11 & $30 \%$ \\
\hline Teacher & 69 & 23 & $33 \%$ \\
\hline Parent & 124 & 40 & $32 \%$ \\
\hline Student & 90 & 44 & $49 \%$ \\
\hline Total & 320 & 118 & $37 \%$ \\
\hline
\end{tabular}

3.2.1. Responses of the sample of the study for the previous reasons are as follows:

The principals of high school, with a ratio of (30\%) agreed that distance learning is not suitable for the students in the high school stage, from their own points of view for the following reasons:

i. The students miss punctuality and time respect. ii. The students are deprived from exercising the ethics of students such as respect of the teachers and the academic campus.

iii. It is not suitable for the students who are not good at using the computer and the internet or even do not own it.

iv. It affects health and weakens the eye sight.

The teachers, with a ratio of (33\%) agreed on inappropriateness of distance learning for the stage of high school, from their points of view for the following reasons:

i. It is not suitable for practical and applied lessons.

ii. Difficulties in performing and assessment of quizzes.

iii. The students need direct social communication in such stage of age.

iv. The students are deprived from the direct human communication including sight and body communication such as handshaking, patting on the shoulders.

v. The negative effect on the students' handwriting skills.

Parents and guardians, with a ratio of (32\%) agreed on inappropriateness of distance learning for the stage of high school, from their points of view for the following reasons:

i. The students need the daily direct follow up by the teachers.

ii. It may lead to social isolation.

iii. It reduces the students' movement and deprives them from the daily sports in the school yard.

Students of the high school stage, with a ratio of (49\%) agreed on inappropriateness of distance learning for the stage of high school, from their points of view for the following reasons:

i. It leads to feeling bored after a period of time.

ii. It makes the students stay at home and prevents them from having fun and meeting friends.

iii. It helps in cheating in exams.

iv. It is unsuitable for careless students.

3.3. All individuals of the sample of study agreed on the possibility of applying distance learning in the high school stage if the following specifications and conditions are provided:

i. Getting ready with the trained human cadres and qualifying educational leaders for such a kind of education.

ii. The necessity of experimenting and doing scientific researches before application.

iii. Considering the customs, the traditions and the national identity of each society. 
iv. Imposing the system by the governments and getting away from competing commercial establishments.

v. Using modern and suitable teaching strategies suitable for this kind of education.

vi. Explaining the sound instructions in dealing with the computer and the internet.

vii. Setting missions and homework to assess the practical skills.

viii. Making sure of the full control of the teacher inside the virtual classroom.

ix. Official recognition of the high school certificate issued from this system so that the universities accept any student that used the distance learning system.

x. The necessity of continuous censorship and serious follow up by the supervisors and officials.

xi. Recognizing the weakness points and the causes of the failure of this system, at some universities and working to avoid them.

xii. Combining the different forms of electronic learning such as simulation, virtual labs, virtual environment and virtual museums. This helps distance learning to be stronger.

xiii. Availability of credibility.

xiv. Setting powerful rules for exams and assessment through this system so that cheating cannot be done. The modern methods of assessment by all means and not to depend wholly on the traditional exams.

xv. To be done in a correct educational form according to powerful rules to maintain a certain level of quality.

xvi. To be available in holidays and official vacations.

xvii. To be quick in implementation for being important.

\section{Recommendations}

Through the results of the study, we conclude the following:

i. Doing experimental researches about the effect of distance learning on academic benefits for the high school students.

ii. Making research studies about the effect of distance learning on the psychological and the social side for high school students.

iii. Making research studies about the effects of distance learning on the health side of the high school students.

iv. Spreading enlightenment about the advantages of distance learning.

v. It is necessary to use the programs and applications on the internet to achieve the goals of education. vi. Including the curricula and methodologies that are suitable for distance learning within the curricula of education colleges.

vii. Mixing the traditional education with distance learning to benefit from the advantages of distance learning, together with maintaining the educational values of traditional education.

\section{Conclusion}

Distance learning is a means but not an end. Entering this system in the public education, wholly as a virtual school or partly mixed with the traditional education to be suitable to the circumstances of the learner, has become an urgent need in this era. Having many advantages and avoiding the obstacles of time and place makes it required for solving many of the problems that face the academic community. Fairness and equality will be achieved and knowledge will be available to everyone via distance learning as long as it has flexibility in what, when, where and how they learn. However, required quality will not be achieved without strong conditions, standards and rules besides continuous follow up by the governments. It will have basic changes in the educational field with which the role of the teacher, the students and the school administration will change. Also, new methods of teaching will appear.

All of this will require full research studies and well planned strategies as well as political and financial support to make it appropriate for application in the public education.

\section{References}

[1] Al-Mubarak, Ahmed, "The Effect of Teaching by use of Virtual Classes through the Internet on the students' knowledge obtainment at the educational colleges in the technologies of Education and communication at King Saud University”. Master Research Study, Education College, King Saud University, the Kingdom of Saudi Arabia the Kingdom of Saudi Arabia, Riyadh, (2005).

[2] Hussain, I., "A Study of Student's Attitude Towards Virtual Education in Pakistan" Turkish Journal of Distance Education, Volume: 8 Number: 2 Article: 6, (2007)

[3] Shawashrah, Atif. "The University and Adults open Education" The conference of The Role of the Private Arab Organizations in achieving development goals in Arab Countries, Participation for Building the Future, Kuwait from 18-20 November 2006.

[4] Grunewald, M. et al, "Web-based Training in Radiology - Student Course in the Virtual University of Bavaria” The Internet and Higher Education, Vol 6, No. 3, 3rd Quarter, PP263-276, (2003). 
[5] Nashwan. Yacoub, "Management of Distance Learning and the University Open Education" , Dar Al-Furqan , Jordan, (2004).

[6] Samirah. Al-Jifri, "Effects of Using Virtual Classes on Developing Strategic Skills for Female Educational Supervisors” A Master Research study (unpublished), King Abdul Aziz University, KSA Jeddah, (2009)

[7] Visser. JAN, "Learning without frontiers: Distance Education for the nine high-population countries" A concept paper based on the Informal Planning Meeting on Distance Education of the nine high-population countries, Manila, 17-19 February 2004.

[8] Virkus. Sirje, “A Conceptual Model for Designing and Delivering Distance Education in Library and Information Science Education in Estonia" 64th IFLA General Conference 16 - 21 August 2008.

[9] Morino. M, "Implications for higher education in the information age” Inaugural Symposium, (2007). 